\title{
Marine Debris Mitigation - Plastic Neutrality through a Credit System in Southeast Asia
}

\begin{tabular}{|c|c|}
\hline Journal: & $\begin{array}{l}\text { Waste Management \& Research: The Journal for a Sustainable Circular } \\
\text { Economy }\end{array}$ \\
\hline Manuscript ID & Draft \\
\hline Manuscript Type: & Mini-review articles: 50,000 characters \\
\hline $\begin{array}{r}\text { Date Submitted by the } \\
\text { Author: }\end{array}$ & $\mathrm{n} / \mathrm{a}$ \\
\hline Complete List of Authors: & Lee, Maggie Ka Ka; United Nations Environment Programme, \\
\hline Keywords: & $\begin{array}{l}\text { marine litter, plastics, responsible production, Southeast Asia, credit } \\
\text { system }\end{array}$ \\
\hline Abstract: & $\begin{array}{l}\text { In the Bangkok Declaration of } 2019 \text {, the Association of Southeast Asian } \\
\text { Nations (ASEAN) vowed to significantly reduce marine litter. Efforts to } \\
\text { reduce unnecessary plastic consumption have been seen in social } \\
\text { movements, corporate policies and most noticeably, in regulatory control } \\
\text { in the form of bans for specific types of single-use plastic items. } \\
\text { Corporate engagement to manage the plastic value chain in ways that } \\
\text { commit to the creation of circular economies is attaining popularity. The } \\
\text { reduction of plastics in the private-sector is allegedly ongoing but } \\
\text { intangible in Southeast Asia. While recovery and collection innovations } \\
\text { are underway for application and picking up speed, an unfathomable rate } \\
\text { of marine litter entering waterways is still aggravating the bigger- } \\
\text { thanever problem of plastic marine debris in Southeast Asia. Responsible } \\
\text { production has long adopted the concept of credits. Carbon credits are } \\
\text { the most notable one, while palm oil credits are also prominently } \\
\text { purchased by manufacturers to offset any palm oil content that is not yet } \\
\text { sourced from certified sustainable suppliers. "Plastic neutrality" in the } \\
\text { form of credit purchasing by manufacturers could likely be the final } \\
\text { missing piece of the puzzle picturing a circular economy. In theory, the } \\
\text { credit system could serve as an offsetting mechanism to recover from } \\
\text { nature an equivalent or higher amount of plastics to be produced by the } \\
\text { credit-purchasing responsible manufacturer. This paper explores how } \\
\text { neutrality through Plastic Credits, similar to the existing carbon and } \\
\text { sustainable palm oil credits, could be applied in Southeast Asia. }\end{array}$ \\
\hline
\end{tabular}

\section{SCHOLARONE ${ }^{\text {m }}$ Manuscripts}




\section{Marine Debris Mitigation - Plastic Neutrality through a Credit System in Southeast Asia}




\begin{abstract}
Sustainable Development Goals (SDG) 12: Responsible consumption and production and 14: Life Below Water coincide in the targeting of the problem of plastic marine litter, which has been garnering immense media attention in the recent years. In the Bangkok Declaration of 2019, the Association of Southeast Asian Nations (ASEAN) vowed to significantly reduce marine litter. Efforts to reduce unnecessary plastic consumption have been seen in social movements, corporate policies and most noticeably, in regulatory control in the form of bans for specific types of single-use plastic items. A paradox exists as, arguably, civilization cannot sustain its current developmental momentum without the use of plastics, especially with the COVID-19 pandemic demanding higher levels of hygiene. This is the argument that is seen coupled with mass bans of single-use plastics, including packaging material and personal protective equipment. Corporate engagement to manage the plastic value chain in ways that commit to the creation of circular economies is attaining popularity. While reduction and substitution are being considered, the status quo of the scale of the production of plastics is still expected for the next few years as life cycle assessments (LCA), test trials of consumer acceptance towards novel delivery mechanisms and other forms of innovation are emerging. The reduction of plastics in the private-sector is allegedly ongoing but intangible in Southeast Asia. While recovery and collection innovations are underway for application and picking up speed, an unfathomable rate of marine litter entering waterways is still aggravating the bigger-than-ever problem of plastic marine debris in Southeast Asia.
\end{abstract}

Responsible production has long adopted the concept of credits. Carbon credits are the most notable one, while palm oil credits are also prominently purchased by manufacturers to offset any palm oil content that is not yet sourced from certified sustainable suppliers. The concept of credits for plastics has been proposed but remains much less explored than their counterparts for other commodities. "Plastic neutrality" in the form of credit purchasing by manufacturers could likely be the final missing piece of the puzzle picturing a circular economy. In theory, the credit system could serve as an offsetting mechanism to recover from nature an equivalent or higher amount of plastics to be produced by the credit-purchasing responsible manufacturer. This paper explores how plastic neutrality through Plastic Credits, similar to the existing carbon and sustainable palm oil credits, could be applied in Southeast Asia.

Keywords: marine litter, plastics, responsible production, Southeast Asia, credit system 


\section{Introduction - Credit systems to account for environmental externalities}

Credit systems have long been in the field of environmental protection - they have been considered to provide the ethical "right to operate" for companies that wish to produce, consume or emit certain products or by-products that are coupled with known externalities or undesirable practices that have a negative impact on the environment (van Riel, Bush, van Zwieten, \& Mol, 2013). The most noteworthy and well-known environmental credit system is arguably the carbon credit system. Through the purchase of credits, individuals and organizations can more sustainably procure, produce and consume certain commodities, products or by-products and address the environmental externalities in various ways, either by offsetting or a newer concept that is called insetting (Gallemore \& Jespersen, 2019). Carbon offsetting is normally referred to as reducing an entity's carbon footprint according with the amount of carbon-equivalent of greenhouse gases (GHG) that would be produced by the entity's value chain by purchasing credits from an external compensation project that generates a carbon-negative effect (Cooper, 2018). On the other hand, similarly, carbon insetting offers also a reduction of carbon footprint, but in this case, by compensating for the carbon footprint through projects within the value chain of the entity (Cooper, 2018).

\section{Case studies}

\section{Carbon credits - mitigating climate change}

At the end of the previous millennium, the concept of offsetting was made known to the world through the Kyoto Protocol, its objectives being to reduce GHG emissions to mitigate and alleviate global climate crises (UNFCCC, 1997). Under the Kyoto Protocol, there are many 
options from which a business entity can purchase carbon credits - one such example forestry projects, which produce wood for fuel to replace fossil fuels and energy-intensive materials, as well as generate trees that absorb carbon dioxide (van der Gaast, Sikkema, \& Vohrer, 2016). With the purchase of credits from projects that are reducing carbon emissions, businesses can compensate for their emissions of greenhouse gases necessary for their planned productions (Bumpus \& Liverman, 2008). In theory, the total amount of global GHG emissions could be controlled through the buying and selling of carbon credits through this trading process (Gupta, 2011). It is also important to note that carbon credits act as supplementary ways to reduce one's emissions from their own controllable surroundings, be it a household, a company or a country, and not as the primary way (Bumpus \& Liverman, 2008). As per the Kyoto Protocol's First Commitment Period, primary carbon reduction is done in the form of an actual reduction of GHG emissions within the respective committed nations (UNFCCC, 1997).

\section{Certified sustainable palm oil credits - preventing biodiversity loss and} conserving habitats

Palm oil, one of the most voluminous agricultural products in the world, has been a controversial commodity with its production methods and externalities heavily criticized (Gassler \& Spiller, 2018). The most significant environmental issue linked to palm oil production is the deforestation of primary and secondary forests (Ivancic \& Koh, 2016). The negative impact of deforestation is further amplified when taking place within the borders of the two largest palm oil-producing countries of the world, Indonesia and Malaysia, home to approximately $11 \%$ of the world's remaining tropical forests and important habitats for the biodiversity-abundant area (Ivancic \& Koh, 2016). Other environmental detriments associated with palm oil production 
include the slashing and burning that produce haze and GHG emissions and irreversible conversion of peatland to plantations that lead to biodiversity decline (Lam \& Lee, 2011).

In response to a pressing global call for sustainably produced palm oil and to promote sustainable palm oil and oil palm products through a reviewed set of standards, the Roundtable on Sustainable Palm Oil (RSPO) was founded in 2004 by the World Wide Fund for Nature (WWF) and producers and buyers of palm oil (Roundtable for Sustainable Palm Oil, 2020). Within the multilayered system of RSPO-certified sustainable palm oil classification, RSPO offers a credit system as an entry point to sustainable palm oil sourcing of which buyers of palm oil could choose to buy in lieu of physical certified sustainable palm oil (RSPO, 2020). According to RSPO, by buying credits, buyers of palm oil would contribute to the creation of a higher demand for sustainable palm oil products in the global market.

Palm oil credits were marketed under the GreenPalm system until 2017 (Roundtable for Sustainable Palm Oil, 2020). Since then, RSPO Credits, also known as Book \& Claim, have been sold to buyers of palm oil (RSPO, 2020). In the context of crude palm oil, one RSPO Credit represents one metric tonne of certified sustainable palm oil distinctively produced by independent smallholders. Every credit that is purchased would provide a premium to a producer that has produced one metric tonne of palm oil in accordance to the RSPO Principles and Criteria (Roundtable for Sustainable Palm Oil, 2020). Benefits of the palm oil credit system for the buyer include having no sourcing changes from the supply chain point-of-view - the organization could offset up to the entirety of their palm oil supply through purchasing the full volume of their palm oil consumption in RSPO Credits, in the meantime, the supply chain does not need to adopt any actual changes and replace all of their raw materials composed of oil palm to RSPO certified sustainable palm oil alternatives. The downsides for the sustainability of palm oil production in having the credits is that while buyers of RSPO Credits have offset their palm oil supply with the credits, the actual demand for physical certified sustainable palm oil 
would not change until the buyer commits to a sourcing change to physically adopt RSPO certified sustainable palm oil.

\section{Background: Plastic marine litter crisis and solutions thus far}

Plastic marine litter has been reported as an environmental problem as early as the 1970 s (Bergmann, Gutow, \& Klages, 2015). Using current growth figures for future projections, the flow of plastic into the ocean per year will almost triple by the year 2040 to $29,000,000$ metric tons, which equals to having $50 \mathrm{~kg}$ of plastic litter per metre of coastline across the world (Pew Charitable Trusts, SYSTEMIQ, 2020). East Asia and the Pacific, inclusive of Southeast Asia, is the source of an astounding $60.6 \%$ of global mismanaged plastic waste (Ritchie, 2018). Five of the top ten countries with the highest mass of mismanaged plastic waste are in Southeast Asia (Jambeck, et al., 2015). In Malaysia, for instance, land-based marine litter, ranging from 1 to 30 $\mathrm{mm}$ in size, are abundant in the beaches (Fauziah, Liyana, \& Agamuthu, 2015). There are arguments that plastic marine litter is a problem of waste management, as studies show that land-based marine litter has increased over the last few decades (Bergmann, Gutow, \& Klages, 2015). Yet leakage is not the only cause of the problem, the continued growth of plastic consumption, despite the issue of marine litter coming into public knowledge in recent years, is the contested top cause of increased plastic marine litter. Plastic leakage in oceans will continue to be over 9,000,000 metric tons per year until 2030 due to the discrepancy between the growth in waste management capacity with the even faster growth in plastic consumption (WWF, 2019). 
After the Fifth International Marine Debris Conference held in Honolulu in 2011, a framework for comprehensive and global effort to reduce ecological, human health, and economic impacts of marine litter was created - the Honolulu Strategy (UNEP and NOAA, 2011). In the Honolulu Strategy document, the first of 3 goals that were identified as the components of the strategic framework is Goal A: Reduced amount and impact of land-based sources of marine debris introduced into the sea (UNEP and NOAA, 2011). Contributing to Goal A are 7 sub-strategies, none of which include any ideas for the reduction of the production of plastics, while the reduction of solid waste was mentioned aplenty as a recommended way to prevent marine litter (UNEP and NOAA, 2011). From around 2015, the discussion of marine litter solutions has significantly shifted from education and the collection or recovery of marine debris to circular economy and accountability of producers of plastics (WWF, 2019; Williams \& Rangel-Buitrago, 2019).

Legislative interventions, including bans and levies on the consumption of day-to-day, free to obtain disposable plastic items, became a popular approach for countries around the globe. Recent studies have argued that the curbing of vast amounts of plastic waste produced is a much-needed measure to address the growing marine litter problem (Walker \& Xanthos, 2018; Gallo, et al., 2018). The impetus to legally limit the amount of single-use plastics produced is driven by the growing voice from the international academic community, calling for governments to intervene by imposing sophisticated policy frameworks from the points of design and production (ten Brink, et al., 2018; Gallo, et al., 2018). As of July 2018, 127 countries out of 192 countries studied have adopted some form of regulation or measure for plastic bags (UNEP, 2019). To name a few examples in Asia, India has imposed bans on plastic bags in 2002 and 2005, while Hong Kong has adopted a plastic bag levy as early as 2009 (Xanthos \& Walker, 2017). Nevertheless, no significant legislative change has been seen in the area of consumer product packaging so far. Despite the recent effort to escalate legislative intervention to prevent 
marine litter, studies have identified potential gaps, which include the limits of existing policy instruments, deficiencies in the legislation and poor enforcement of regulations, sporadic international or regional cooperation and the lack of science-based data on marine litter (Bergmann, Gutow, \& Klages, 2015). In Southeast Asia, namely the Association of Southeast Asian Nations (ASEAN), the legislative framework for packaging material sustainability is nonexistent, while rapid population growth and economic development leading to increased consumption in the region is leading to severe deficiencies of standards in prevention of plastic marine litter (UNEP SEA circular, 2019).

A region of numerous success stories in achieving very high recycling rates, the European Union (EU) has strategies to address the planned targets throughout the plastic supply chains from an end-to-end point of view - beginning with product design to covering post-consumer and end-of-life, by means of stimulating regional capacity of recycling and warranting demand for recycled plastics, as well as implementing legislature (Filho, et al., 2019). Extended producer responsibility (EPR) schemes, first introduced by Thomas Lindhqvist in 2000 , have had positive effects on recycling rates in countries that have refined implementation to mandate the collection and ensure technical recyclability (Lindhqvist, 2000; Filho, et al., 2019). Solutions that connect known working schemes together are much necessary as other remedies continue to show no progress with marine debris reduction.

\section{Circular economy development in Southeast Asia}

Grass-root movement in the developed world has been even more demanding than recommendations by academia - there are now challenges for zero-waste lifestyles, mass criticism directed towards manufacturers and retailers on the amount of plastics in their products, and even businesses that have committed to drastic reductions in plastics (Jennings, 
2019). Moreover, in the search for alternatives to replace plastics, studies have shown that properties of plastic polymers that protect food products outweigh known environmental costs of alternatives, such as water and energy consumption, in LCAs (Abejon, Bala, Vázquez-Rowe, Alcado, \& Fullana-i-Palmer, 2020; Humbert, Rossi, Margni, Jolliet, \& Loerincik, 2009). Reusability became a topic of discussion among consumers who are conscious of their plastic footprint. Non-packaging single-use plastic items, most notably, cups for made-to-order beverages and plastic bags for groceries, have been widely suggested to be replaced by "bringyour-own" reusables since the early 2010s (Wabnitz \& Nichols, 2010). As for on-product packaging, Accorsi et al. have conducted LCAs on reusable containers for food catering and compared results with conventional single-use material such as plastics. Results indicate that the environmental impact of reusables is highly dependent on disposal policies and transportation (Accorsi, Cascini, Cholette, Manzini, \& Mora, 2014). As for perishables, pharmaceutical and medical products, and other products that rely on individual or pressureresistant packaging, no peer-reviewed LCA research has been found on reusable packaging, possibly due to lack of practical alternatives. To strike a balance between impactful reductions in plastic packaging use and other environmental costs such as carbon footprint in logistics and food waste, businesses are stuck between a rock and a hard place, as few researchers can proclaim that the plastic marine litter crisis should be prioritized over global climate crises. In addition to all environmental concerns, economic feasibility is an impenetrable wall that new solutions, no matter how environmentally friendly, cannot traverse unless they offer pricing that is remotely competitive compared with plastics.

In one study conducted in five countries in Southeast Asia, $91 \%$ of consumers consider themselves concerned about plastic waste issues, while only $38 \%$ are interested to recycle or convert their waste into useful products (UNEP SEA circular, 2020). Consumer action to recycle alone would not be sufficient to create a circular economy for plastics in Southeast Asia. It is 
necessary to have a system in which businesses are incentivized to adopt recycled material, and therefore create demand for recycling. Southeast Asian private-sector concern about plastic waste issues is reassuring $-82 \%$ of surveyed businesses feel extremely concerned, while fewer than half feel their current efforts are enough to mitigate the problem (UNEP SEA circular, 2020).

\section{Discussion: Plastic neutrality - a marine litter prevention}

\section{proposition for plastic-generating businesses in Southeast Asia}

Multinational corporations (MNCs) such as German-headquartered consumer goods giant Henkel and Swiss-based pharmaceutical mogul Novartis have published global "zero-waste" or "plastic neutral" sustainability goals on packaging, namely becoming zero-waste by 2025 through closed-loop recycling and plastic neutral by 2030, respectively (Henkel, 2020; Novartis, 2020). However, with prices of crude oil, the petrochemical raw material for plastics, reaching an

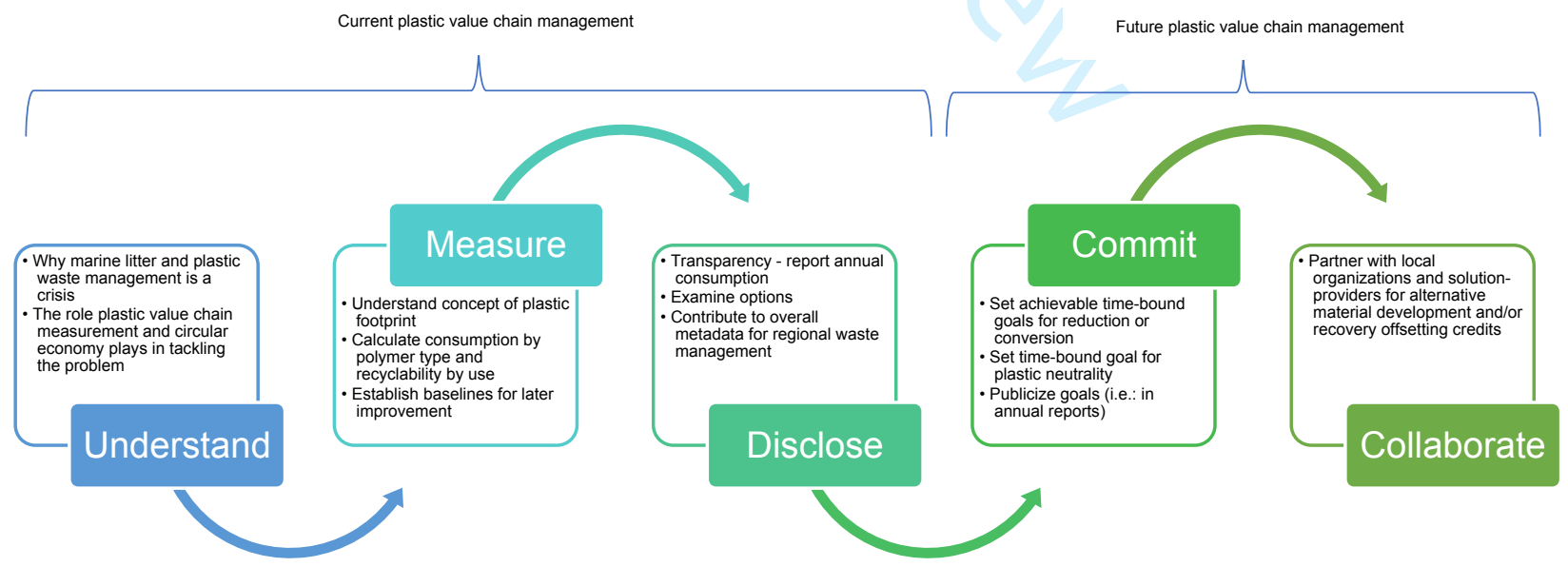

Figure 1 Proposed step-by-step strategy for Southeast Asian businesses to become plastic neutral

all-time low at negative price points (Apergis \& Apergis, 2020), the relatively infinitesimal cost to manufacture virgin plastics is driving recycled plastic out of competition, rendering recycling an 
irrelevant and undesirable process. Heightened difficulty to source quality recycled plastic could hinder businesses to commit further towards plastic neutrality.

A series of steps inclusive of understanding, measuring, and disclosing current plastic footprint, and committing and collaborating to reduction and neutrality is proposed to form an overall strategy to facilitate Southeast Asian business commitments towards a circular economy and plastic neutrality (Figure 1). While the first two steps are widely adopted by multinational MNCs, the necessity of managing a business' plastic value chain is still a nascent concept in Southeast Asia. The final step in current plastic value chain management is adopting transparency in the form of publicizing plastic footprint, for instance, in sustainability and/or annual reports. After businesses take up management of their current plastic value chains, time-bound commitments towards plastic neutrality would be the most important subsequent step.

In this paper, plastic neutrality is defined as:

1) adopting $100 \%$ post-consumer, recycled material, and/or;

2) recovery and recycling of legacy plastic debris in nature or landfills, to the extent of the entire plastic footprint by offsetting or insetting

By committing to plastic neutrality, businesses would have more incentives to reduce current plastic footprint, so as to ease future transitioning difficulty in becoming plastic neutral. It is important to note that by reducing plastic footprint, especially that of items such as food containers, environmental externalities such as GHG emissions could be reduced (Yano, Hirai, \& Sakai, 2014). Existing plastic value chain transforming programs for businesses in Southeast Asia, such as WWF-Singapore's Plastic ACTion (PACT), encourage businesses to commit to reduce plastic footprint and to plastic neutrality by 2030 (WWF-Singapore, 2020). 


\section{Plastic Credit system - standardized marine debris recovery ledger}

While reductions of plastic consumption require value chains reimagined, recovery of plastics has a much lower technical hurdle. Beach/coastal and waterway cleanups have been gaining popularity in corporate social responsibility programs. Some speculate that such activities under the attention-grabbing name of combatting marine litter are desirable for the "photograph opportunities" they offer (Stafford \& Jones, 2019). In fact, the efficacy of beach cleanups as a solution for marine debris has been observed to be dependent on many factors, such as the input period and oceanic seasonal variations (Kataoka \& Hinata, 2015). Regardless of the intention of corporate-sponsored beach cleanups, it is undeniable that any removal of plastic from nature, no matter how little, is facilitative to resolving the problem and should be encouraged. Despite so, unassuming consumers may not be able to differentiate the efficacy of a quarterly beach clean-up from a time-bound plastic neutrality goal.

With the primary objective of mainstreaming recovery of plastics in nature and secondary objectives of widening the supply base of recyclates so to stimulate recycling, a Plastic Credit ledger system is proposed as part of the business strategy (Figure 1).

\section{Prerequisites for adopting Plastic Credits}

Plastic neutrality must not be the first step in plastic footprint stewardship. Businesses looking to declaring plastic neutrality through Plastic Credits must already have a plan to reduce their plastic footprint through plastic value chain measurement and management - inclusive of, but not limited to, circular designs and material selection based on LCA results. This is analogous to how carbon credits are only supplementary to the overall GHG reductions necessary for any entity. 
Plastic value chains should undergo all prerequisite steps listed below before proceeding to

neutralization through Plastic Credits (Plastic materials: polyvinyl chloride (PVC), 2012):

These steps are necessary to ensure that plastic value chains are life-cycle optimized. Moreover, they provide the assurance that, prior to opting for neutralization, businesses have undertaken due diligence by minimizing the environmental impact of any unavoidable plastic footprint.

\section{Properties of the Plastic Credits}

The Plastic Credit system's key objective is to help businesses quantify the extent of neutralization of their plastic footprint either by offsetting, by means of activities financially supported but separate from the corporation's core business, or insetting, from plastic-recovery activities like beach cleanups conducted by employees. Conditions adhering to the issuance of Plastic Credit include that the recovered PCPW must be:

1) recyclable (i.e.: acceptable by a local recycler to be recycled), and

2) recovered from sites not regarded as formal disposal sites.

Akin to how the carbon credit aligns all GHG to a carbon-equivalent ratio, the Plastic Credit system needs to have a basic measurement unit to standardize all recyclable plastic polymers, possibly with what is commonly regarded as the most recycled, highly versatile polymer polyethylene terephthalate (PET/PETE). As seen in the RSPO palm oil credit system, the 
Plastic Credit system must also be governed by a centralized standards body that maintains the standard with principles and criteria reviewed regularly and LCAs performed as necessary to ensure the ledger does not fall into obsolescence due to new technologies emerging in recycling and alternative production.

Polymer-specific and recyclability-based compensation

Recyclability of plastic polymers is largely dependent on the polymer type, as well as the form of the original plastic item (Faraca \& Astrup, 2019). Out of the roughly 30 types of materials that are in the family of plastics, there are 4 polymers that have consistently reputed recycling values in Southeast Asia, especially in Singapore - polyethylene terephthalate (PET), low-density polyethylene (LDPE), high-density polyethylene (HDPE) and polypropylene (PP) (Singapore Environment Council, 2018). The ledger should be based on the type of polymer, which further enhances traceability and reliability to enable closed-loop recycling.

Recyclability is hinged on the profits generated from sales of recycled material, whereby recyclers may reject materials that require too much processing (cleaning, sorting, etc.) for the overall recycling to be economically worthwhile. With no segregated collection for PCPW, recyclers resort to manual or technical sorting, which is an energy-intensive process that requires high initial investment in machinery and high maintenance costs (Feil, Pretz, \& Jansen, 2016). Therefore, compensation should be linked to recyclability by the batch - recovery materials that have a higher possibility of having a "next life" would result in higher compensation rates.

Involvement of informal sector, coastal and affected communities

The centralized Plastic Credit standards body should also safeguard social aspects of the credits. The collective of individuals and groups engaged in waste services, but are not funded, recognized or formally allowed to perform such activities by the authorities are referred to as the 
informal sector (Aparcana, 2017). The informal sector's agility and widespread coverage have been found to add value to formal solid waste collection in Southeast Asia (Romallosa \& Kraft, 2017; Hoang, Ishigaki, Kubota, Yamada, \& Kawamoto, 2019). It is estimated that the informal sector has enabled Bangkok's city administration to avoid approximately 15.8 million USD per year in waste management costs, which is even higher than the city's spending on formal waste collection (United Nations ESCAP, 2019). The United Nations Economic and Social Commission for Asia and the Pacific (ESCAP) recommends the recognition of the informal sector by forming informal-formal links (United Nations ESCAP, 2019). Although the Asia Pacific region relies heavily on the informal sector for recovery of recyclates, members of the sector are exposed to tremendous health and socioeconomical threats while having very little access to safety equipment and social services (United Nations ESCAP, 2020).

Coastal and island communities in Southeast Asia are particularly affected by plastic pollution. The marine ecosystems serve as a significant resource for coastal and island communities, providing for their food, livelihoods and income (Phelan, Ross, \& Setiant, 2020). In a 2011 research, it is conservatively estimated that there is a $1-5 \%$ decline in marine ecosystem service delivery as a result of marine plastics (Beaumonta, et al., 2019). As income from fisheries, aquaculture, and tourism deteriorates due to plastic pollution, alternate livelihoods with waste management may present new opportunities for affected coastal and island communities. The Plastic Credit system proposed for Southeast Asia involves and relies on the informal sector and affected and coastal communities for the collection and recovery of plastic debris and as a form of solid waste management. These groups are recognized as the primary PCPW recovery agents and should be given a fair wage for their labour. With the upsurge of conversion to recycled plastics as publicized in corporate circularity commitments, the demand for recyclates is most likely to increase, which could give rise to stability to the recycling industry. With a more 
stable recycling industry, it could be possible that a minimum reward per unit of recyclates recovered be established to ensure a fair wage in Plastic Credit markets for recovery agents.

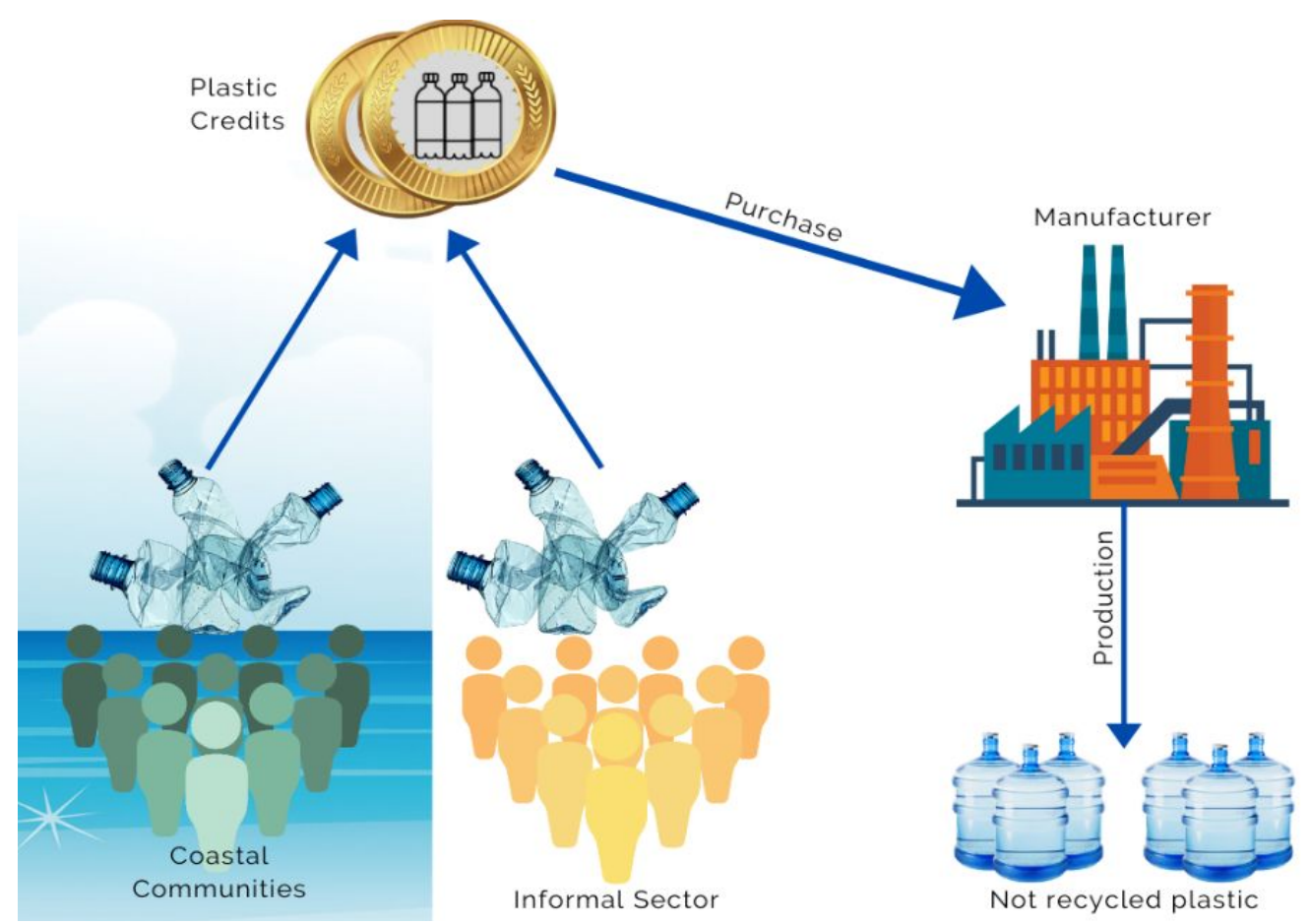

Figure 3 A simplified depiction of the proposed Plastic Credit system for Southeast Asia involving local communities as recovery agents

\section{Benefits of the Plastic Credit system}

The objective of the Plastic Credit system is to create a standardized ledger for PCPW recovery for the goal of "closing the loop" - establishment of true circularity for plastics. Aside from environmental benefits, there could be significant socio-economic benefits in neutralizing plastic footprint through Plastic Credits.

Traceability to enable closed-loop recycling Closed-loop recycling consists of recycling PCPW into products of similar usage and properties as the original recyclate (Eriksen, Christiansen, Daugaard, \& Astrup, 2019). One of the major hurdles being impurities (Eriksen, Christiansen, Daugaard, \& Astrup, 2019), as demonstrated by 
the national regulations on food packaging in Thailand. As of 2019, notification No. 295/2548 (2005) of the Thai Food and Drug Administration (FDA) stipulates the prohibition of the use of recycled plastic for food contact packaging hence food-grade packaging made from recycled packaging is not allowed in Thailand (Thesasilpa, 2019). The prohibition is in place primarily due to concerns over chemical and organic contamination of the recyclate, especially those contaminated by fertilizers and other toxic substances (Thesasilpa, 2019). With a regulated ledger that states the specifics of the recovery condition, ensuring the source of the recyclate stream (i.e.: PET beverage bottles), closed-loop recycling (i.e.: bottle-to-bottle) could be rendered reliable.

The following table (Table 1) illustrates some of the projected outcomes of implementing the Plastic Credit system, as well as the consequent benefits for other parties involved in the plastic value chain.

Table 1: Projected outcomes of Plastic Credit system and benefits for the recycling industry, manufacturing industry and local communities

\begin{tabular}{|c|c|c|c|}
\hline $\begin{array}{l}\text { Projected outcome from } \\
\text { Plastic Credit system }\end{array}$ & $\begin{array}{l}\text { Benefits for the } \\
\text { recycling } \\
\text { industry }\end{array}$ & $\begin{array}{l}\text { Benefits for the } \\
\text { manufacturing industry }\end{array}$ & $\begin{array}{l}\text { Benefits for local } \\
\text { communities }\end{array}$ \\
\hline $\begin{array}{l}\text { Creating a standardized } \\
\text { ledger for each recyclable } \\
\text { polymer, aligned by } \\
\text { recyclability }\end{array}$ & $\begin{array}{l}\text { Higher } \\
\text { recyclability of } \\
\text { recyclate stream } \\
\text { (better quality) }\end{array}$ & $\begin{array}{l}\text { Increased interest in } \\
\text { adopting recyclable } \\
\text { material }\end{array}$ & $\begin{array}{l}\text { Higher per unit } \\
\text { remuneration of } \\
\text { recovered plastics due } \\
\text { to better quality }\end{array}$ \\
\hline $\begin{array}{l}\text { Employment of } \\
\text { local/affected communities } \\
\text { for year-round work }\end{array}$ & & $\begin{array}{l}\text { Corporate endorsement } \\
\text { for environmental and } \\
\text { social impact in }\end{array}$ & $\begin{array}{l}\text { Human rights-based } \\
\text { employment for } \\
\text { fishing/coastal }\end{array}$ \\
\hline
\end{tabular}




\begin{tabular}{|c|c|c|c|}
\hline & & $\begin{array}{l}\text { offsetting/insetting partial } \\
\text { or total plastic footprint }\end{array}$ & $\begin{array}{l}\text { communities with fair } \\
\text { wages }\end{array}$ \\
\hline $\begin{array}{l}\text { Increased and more } \\
\text { systematic } \\
\text { recovery/collection } \\
\text { activities by the informal } \\
\text { sector }\end{array}$ & \multirow[t]{2}{*}{$\begin{array}{l}\text { More stable and } \\
\text { more reliable } \\
\text { recyclate stream }\end{array}$} & \multirow[t]{2}{*}{$\begin{array}{l}\text { Increased feasibility of } \\
\text { sustainability goals for } \\
\text { higher recycled material } \\
\text { content }\end{array}$} & $\begin{array}{l}\text { Stability in income for } \\
\text { the local communities } \\
\text { employed }\end{array}$ \\
\hline $\begin{array}{l}\text { Increased interest for local } \\
\text { groups to conduct regular } \\
\text { volunteer-based beach } \\
\text { clean-ups }\end{array}$ & & & $\begin{array}{l}\text { Cleaner local } \\
\text { landscapes, seascapes, } \\
\text { and tourism attractions }\end{array}$ \\
\hline Sorting at point of recovery & \multicolumn{2}{|c|}{ Traceability for closed-loop recycling } & $\begin{array}{l}\text { Relatively higher per } \\
\text { volume }\end{array}$ \\
\hline
\end{tabular}

\section{Links to and applications in other schemes and standards}

\section{Plastic Accounting}

At the point of submission of this paper, The Guidelines for Leadership in Corporate Plastic Accounting is being developed by the $3 R$ Initiative, a cross-sectoral alliance of manufacturing leaders and environmental consultancies, and multiple environmental consultancies (3R Initiative, EA, South Pole, \& Quantis, 2020). The prerequisites and the principles of plastic credits are outlined in detail from the corporate point-of-view. Along with the conditions for Plastic Credits discussed in this paper, a universal standard of plastic accounting using a credit system could be applied to nearly the entire plastic value chain. Claims made by businesses regarding their plastic footprint, offsetting and neutrality could be certified by third party certification entities using this combination of standards. 


\section{Extended Producer Responsibility schemes}

Incentives for PCPW collection could be driven by mandatory deposit refund schemes where waste management is developed and effective, and by Plastic Credits where there is leakage, poor collection rates and/or accumulation of plastics in nature. The two systems should be incorporated into future EPR schemes of Southeast Asia, while transactions of the credits are transparent within the EPR scheme. Southeast Asia has no voluntary and legally mandated national EPR schemes for plastics as of 2020 (WWF, 2019). Since 2019, the government, academia and civil society of Singapore have been exploring the implementation of EPR schemes for plastics in Singapore (Singapore International Chamber of Commerce, 2020; Bea \& Low, 2019) and more recently as announced in September 2020 in Malaysia (Malaysian Medical Council, 2020). While recovery rates of the materials of interest are an important factor in EPR schemes (Peng, Tu, Elahi, \& Wei, 2018), in many low and middle-income countries, effective collection systems for PCPW continue to be a major hurdle in establishing all prerequisites of EPR regulations (WWF Network, 2019). Through the establishment of a Plastic Credit system, EPR schemes can be empowered by a standardized way of incentivizing and compensating the collection of PCPW by polymer type.

ISO standards for circular economy

Another opportunity for synergy prior to the launch of mandatory EPR schemes would be to have the Plastic Credit system merge with voluntary technical standards. The most recently released International Organization for Standardization guideline for recovery and recycling of plastic waste is ISO $15270: 2008$ at the point of submission of this paper. By the term "recovery", ISO standards refer to the recovery of a material through processes, such as mechanical recycling, that render it usable again. It contains no guidance on how PCPW is collected or recovered from nature (International Organization for Standardization, 2008). A more recent publication, ISO standard ISO/TR 23891:2020 outlines the necessity of standards for recycling 
and recovery and touches on the techniques for material recovery (International Organization for Standardization, 2020). The ISO TC/323 Circular Economy certification standard is under development by the International Organization for Standardization (ISO, 2020) and would be an excellent set of standards for the Plastic Credit system to be jointly integrated with. Businesses that wish to escalate their recognition in contributing to a circular economy should have a plastic neutral goal in order to be rightfully deemed to facilitate circular economies.

\section{Human rights-based approach}

Linkage of the Plastic Credit system to a human rights-based approach is also paramount, as the collection of PCPW in Southeast Asia is often done by informal waste pickers, while coastal communities recover plastic marine litter (UNEP SEA circular, COBSEA, SEI, 2019). There are already numerous known social, economic and health-related adverse effects of marine litter on marginalized groups (UNEP SEA circular, COBSEA, SEI, 2019). In the case of RSPO credits, the social aspects of sustainable palm oil production have been well-addressed. Therefore, the Plastic Credit standards must safeguard collection personnel from health, gender equality and human rights issues to minimize further marginalization of the communities.

\section{Conclusion}

The world came together through the Kyoto Protocol to tackle the problem of climate crises and adopted the carbon credit system. Likewise through the Bangkok Declaration in 2019, Southeast Asia now shows collaborative effort to solve the problem of plastic marine litter - be it in intergovernmental regional plans for marine litter or in business strategies for plastic reduction or even neutrality (UNEP SEA circular, 2019). A solution that combines incentives for businesses to act on plastics with governmental responsibility to remove marine debris is a standardized Plastic Credit ledger system that focuses on the recovery of legacy plastics. The 
system can adopt the fundamental principles of carbon and sustainable palm oil credits wherever applicable and is part of a step-wise approach to encourage businesses to undergo a paradigm shift by managing their plastic value chains and adopting principles of EPR. Aside from the positive environmental impact by removing marine debris from seascapes, Plastic Credits also offer social and economic benefits for the Southeast Asian nations, especially in the coastal areas where tourism and fishing once flourished. The Plastic Credit system needs to be introduced under the consideration of initiatives and policies aiming to reduce plastic production, consumption and accumulation in oceans, such as prospective EPR schemes, plastic value chain management guidelines, and voluntary technical standards. Ultimately, governments and plastic value chain managers should be reminded that the recovery of plastic pollution alone is not the ideal way to solve the problem. Through a composite effort inclusive of the transformation of plastic value chains, legislative enforcement, and best practice recognition, Southeast Asia can break free from its plastic shackles. 


\section{References}

3R Initiative, EA, South Pole, \& Quantis. (2020). Guidelines for Leadership in Corporate Plastic Accounting. Online: 3R Initiative, EA, South Pole and Quantis. Retrieved from https://verra.org/wp-content/uploads/2020/10/Guidelines-for-Leadership-in-CorporatePlastic-Accounting-DRAFT-7-Oct-2020-rev.pdf

Abejon, R., Bala, A., Vázquez-Rowe, I., Alcado, R., \& Fullana-i-Palmer, P. (2020). When plastic packaging should be preferred: Life cycle analysis of packages for fruit and vegetable distribution in the Spanish peninsular market. Resources, Conservation \& Recycling, 155. doi:10.1016/j.resconrec.2019.104666

Accorsi, R., Cascini, A., Cholette, S., Manzini, R., \& Mora, C. (2014). Economic and environmental assessment of reusable plastic containers: A food catering supply chain case study. International Journal of Production Economics. doi:10.1016/j.jpe.2013.12.014

Aparcana, S. (2017). Approaches to formalization of the informal waste sector into municipal solid waste management systems in low- and middle-income countries: Review of barriers and success factors. Waste Management, 61, 593-607. doi:10.1016/j.wasman.2016.12.028

Apergis, E., \& Apergis, N. (2020, May). Can the COVID-19 pandemic and oil prices drive the US Partisan Conflict Index? Energy Research Letters, 1(1). doi:10.46557/001c.13144

Bea, E., \& Low, M. (2019). Extended Producer Responsibility in Singapore's Resource Sustainability Act. NUS Asia-Pacific Centre for Environmental Law Working Paper.

Beaumonta, N., Aanesenb, M., Austena, M., Börgerc, T., Clarka, J., Colea, M., . . Wyles , K. (2019). Global ecological, social and economic impacts of marine plastic. Marine Pollution Bulletin, 189-195. doi:10.1016/j.marpolbul.2019.03.022

Bergmann, M., Gutow, L., \& Klages, M. (2015). Marine Anthropogenic Litter. Springer Open.

Bumpus, A., \& Liverman, D. (2008). Accumulation by Decarbonization and the Governance of Carbon Offsets. Economic Geography, 84(2), 127-155. doi:10.1111/j.19448287.2008.tb00401.x

Cooper, J. (2018). Carbon Insetting: What It Is \& How It Works. Retrieved from Native Energy: https://native.eco/2018/01/carbon-insetting-what-it-is-how-it-works/

Eriksen, M. K., Christiansen, J. D., Daugaard, A. E., \& Astrup, T. F. (2019). Closing the loop for PET, PE and PP waste from households: Influence of material properties and product design for plastic recycling. Waste Management, 75-85. doi:https://doi.org/10.1016/j.wasman.2019.07.005

Faraca, G., \& Astrup, T. (2019). Plastic waste from recycling centres: Characterisation and evaluation of plastic recyclability. Waste Management , 388-398. doi:https://doi.org/10.1016/j.wasman.2019.06.038 
Fauziah, S., Liyana, I., \& Agamuthu, P. (2015). Plastic debris in the coastal environment: The invincible threat? Abundance of buried plastic debris on Malaysian beaches. Waste Management \& Research. doi:10.1177/0734242X15588587

Feil, A., Pretz, T., \& Jansen, M. (2016). Separate collection of plastic waste, better than technical sorting from municipal solid waste? Waste Management \& Research. doi:10.1177/0734242X16654978

Filho, W., Saari, U., Fedoruk, M., lital, A., Moora, H., Kloega, M., \& Voronova, V. (2019). An overview of the problems posed by plastic products and the role of extended producer responsibility in Europe. Journal of Cleaner Production, 214, 550-558. doi:10.1016/j.jclepro.2018.12.256

Gallemore, J., \& Jespersen, K. (2019). Offsetting, Insetting, or Both? Current Trends in Sustainable Palm Oil Certification. Sustainability, 11(5393). doi:10.3390/su11195393

Gallo, F., Fossi, C., Weber, R., Santillo, D., Sousa, J., Ingram, I., . . Romano, D. (2018). Marine litter plastics and microplastics and their toxic chemicals components: the need for urgent preventive measures. Environmental Sciences Europe, 30(1). doi:10.1186/s12302-018-0139-z

Gassler, B., \& Spiller, A. (2018). Is it all in the MIX? Consumer preferences for segregated and mass balance certified sustainable palm oil. Journal Of Cleaner Production, 21-31. doi:10.1016/j.jclepro.2018.05.039

Gupta, Y. (2011). Carbon Credit: A Step Towards Green Environment. Global Journal Of Management And Business Research, XI(V).

Henkel. (2020, March 5). Henkel. Retrieved from Building on strong track record in sustainability - Henkel sets new and ambitious targets for sustainable packaging and climate protection: https://www.henkel.com/press-and-media/press-releases-and-kits/2020-0305-henkel-sets-new-and-ambitious-targets-for-sustainable-packaging-and-climateprotection-1040808

Hoang, N., Ishigaki, T., Kubota, R., Yamada, M., \& Kawamoto, K. (2019). A review of construction and demolition waste management in Southeast Asia. Journal of Material Cycles and Waste Management. doi:10.1007/s10163-019-00914-5

Humbert, S., Rossi, V., Margni, M., Jolliet, O., \& Loerincik, Y. (2009). Life cycle assessment of two baby food packaging alternatives: glass jars vs. plastic pots. The International Journal of Life Cycle Assessment, 14, 95-106. doi:10.1007/s11367-008-0052-6

International Organization for Standardization. (2008). ISO 15270:2008 Plastics - Guidelines for the recovery and recycling of plastics waste .

International Organization for Standardization. (2020). Technical Report ISO/TR 23891:2020 Plastics - Recycling and recovery - Necessity of standards.

ISO. (2020). ISO/TC 323 Circular Economy. Retrieved from https://www.iso.org/committee/7203984.html 
Ivancic, H., \& Koh, L. (2016). Evolution of sustainable palm oil policy in Southeast Asia. Cogent Environmental Science, 2(1). doi:10.1080/23311843.2016.1195032

Jambeck, J., Geyer, R., Wilcox, C., Siegler, T., Perryman, M., Andrady, A., . . Law, K. (2015). Plastic waste inputs from land into the ocean. Science, 347(6223), 768-771. doi:10.1126/science.1260352

Jennings, R. (2019, January 28). The zero-waste movement is coming for your garbage - Forget recycling, meet precycling. Retrieved from Vox: https://www.vox.com/thegoods/2019/1/28/18196057/zero-waste-plastic-pollution

Kataoka, T., \& Hinata, H. (2015). Evaluation of beach cleanup effects using linear system analysis. Marine Pollution Bulletin, 91, 73-81. doi:10.1016/j.marpolbul.2014.12.026

Lam, M., \& Lee, K. (2011). Renewable and sustainable bioenergies production from palm oil mill effluent (POME): Win-win strategies toward better environmental protection. Biotechnology Advances, 29(1), 124-141. doi:10.1016/j.biotechadv.2010.10.001

Lindhqvist, T. (2000). Extended Producer Responsibility in Cleaner Production: Policy Principle to Promote Environmental Improvements of Product Systems. Lund University. Retrieved from https://lup.lub.lu.se/search/ws/files/4433708/1002025.pdf

Malaysian Medical Council. (2020, September). Announcement on Examination for Provisional Registration (EPR). Retrieved from Malaysian Medical Council: https://mmc.gov.my/2020/10/20/announcement-on-examination-for-provisionalregistration-epr/

Novartis. (2020). Waste. Retrieved from Novartis: https://www.novartis.com/ourcompany/corporate-responsibility/environmental-sustainability/waste

Peng, B., Tu, Y., Elahi, E., \& Wei, G. (2018). Extended Producer Responsibility and corporate performance: Effects. Journal of Environment Management, 181-189. doi:https://doi.org/10.1016/j.jenvman.2018.04.068

Pew Charitable Trusts, SYSTEMIQ. (2020, July). Breaking the Plastic Wave: A Comprehensive Assessment of Pathways Towards Stopping Ocean Plastic Pollution. Retrieved from Pew Charitable Trusts: https://www.pewtrusts.org//media/assets/2020/07/breakingtheplasticwave_report.pdf

Phelan, A., Ross, H., \& Setiant, N. (2020). Ocean plastic crisis - Mental models of plastic pollution from remote Indonesian coastal communities . PLOS ONE. doi:10.1371/journal.pone.0236149

Plantations International. (2020). Insetting-Offsetting. Retrieved from Plantations International: https://www.plantationsinternational.com/sweet-chocolate-goes-climate-positive-withcarbon-insetting/insetting-offsetting/

Plastic materials: polyvinyl chloride (PVC). (2012). In G. Akovali, F. Pacheco-Torgal, S. Jalali, \& A. Fucic (Eds.), Toxicity of Building Materials (pp. 23-53). Woodhead Publishing. doi:10.1533/9780857096357.23 
Ritchie, H. (2018). Plastic Pollution. OurWorldInData.org. Retrieved from https://ourworldindata.org/plastic-pollution

Romallosa, A., \& Kraft, E. (2017). Feasibility of Biomass Briquette Production from Municipal Waste Streams by Integrating the Informal Sector in the Philippines. Resources. doi:10.3390/resources6010012

Roundtable for Sustainable Palm Oil. (2020). Factsheet. Retrieved from Roundtable for Sustainable Palm Oil: https://www.rspo.org/file/RSPO-Factsheet.pdf

RSPO. (2020). RSPO Credits. Retrieved from https://rspo.org/rspo-credits

Singapore Environment Council. (2018). Consumer Plastic and Plastic Resource Ecosystem in Singapore - A Position Paper by the Singapore Environment Council. Singapore.

Singapore International Chamber of Commerce. (2020). SICC's Position Paper on Extended Producer Responsibility (EPR) for Packaging in Singapore. Singapore.

Stafford, R., \& Jones, P. (2019). Viewpoint - Ocean plastic pollution: A convenient but distracting truth? Marine Policy, 103, 187-191. doi:10.1016/j.marpol.2019.02.003

ten Brink, P., Schweitzer, J., Watkins, E., Janssens, C., De Smet, M., Galgani, F., \& Leslie, H. (2018). Circular economy measures to keep plastics and their value in the economy, avoid waste and reduce marine litter. Economics Discussion Papers(3). Retrieved from https://www.econstor.eu/bitstream/10419/173128/1/1011145367.pdf

Thesasilpa, J. (2019). Food Packaging Regulations and planned measures to support using recycled plastic in Food industry. Thailand stakeholder consultation on reducing marine litter by addressing the management of the plastic value chain in south East Asia. Bangkok: Bureau of Food, Food and Drug Administration.

UNEP. (2019). Legal Limits on Single-Use Plastics and Microplastics: A Global Review of National Laws and Regulations. Retrieved from United Nations Environment Programme: https://wedocs.unep.org/bitstream/handle/20.500.11822/27113/plastics_limits.pdf?seque nce=1\&isAllowed=y

UNEP and NOAA. (2011). The Honolulu Strategy: A Global Framework for Prevention and Management of Marine Debris. Retrieved from UNEP Document Repository: https://wedocs.unep.org/handle/20.500.11822/10670

UNEP SEA circular. (2019). The Role of Packaging Regulations and Standards in Driving the Circular Economy. Retrieved from http://sos2019.sea-circular.org/wpcontent/uploads/2019/11/FINAL_THE-ROLE-OF-PACKAGING-REGULATIONS-ANDSTANDARDS-IN-DRIVING-THE-CIRCULAR-ECONOMY.pdf

UNEP SEA circular. (2020). Perceptions on plastic waste - Insights, interventions and incentives to action from businesses and consumers in South-East Asia. Retrieved from https://www.sea-circular.org/wp-content/uploads/2020/06/PERCEPTIONS-ONPLASTIC-WASTE_FINAL.pdf 
UNEP SEA circular, COBSEA, SEI. (2019). Marine plastic litter in East Asian Seas: Gender, human rights and economic dimensions. Retrieved from https://www.sea-circular.org/wpcontent/uploads/2019/11/SEI_SEA-circular-1.pdf

UNFCCC. (1997). Kyoto Protocol. Kyoto.

United Nations ESCAP. (2019). Closing the Loop: Innovative partnerships with informal workers to recover plastic waste, in an inclusive circular economy approach - regional policy guide. Bangkok: United Nations. Retrieved from https://www.unescap.org/sites/default/files/Closing\%20The\%20Loop_Regional\%20Polic y\%20Guide.pdf

United Nations ESCAP. (2020). Changing Sails: Accelerating Regional Actions for Sustainable Oceans in Asia and the Pacific. Bangkok: United Nations.

van der Gaast, W., Sikkema, R., \& Vohrer, M. (2016). The contribution of forest carbon credit projects to addressing the climate change challenge. Climate Policy, 18(1), 42-48. doi:10.1080/14693062.2016.1242056

van Riel, M., Bush, S., van Zwieten, P., \& Mol, A. (2013). Understanding fisheries credit systems: potentials and pitfalls of managing catch efficiency. Fish And Fisheries, 16(3), 453-470. doi:10.1111/faf.12066

Wabnitz, C., \& Nichols, W. (2010). Editorial: Plastic Pollution: An Ocean Emergency . Marine Turtle Newsletter.

Walker, T., \& Xanthos, D. (2018). A call for Canada to move toward zero plastic waste by reducing and recycling single-use plastics. Resources, Conservation \& Recycling. doi:doi.org/10.1016/j.resconrec.2018.02.014

Williams, A., \& Rangel-Buitrago, N. (2019). Marine Litter: Solutions for a Major Environmental Problem. Coastal Research, 35(3), 648-663. doi:10.2112/JCOASTRES-D-18-00096.1

WWF. (2019). Legal Framework Study of Extended Producer.

WWF. (2019). Solving Plastic Pollution Through Accountability. Retrieved from World Wide Fund for Nature: https://wwfeu.awsassets.panda.org/downloads/plastic_update_last_03_25.pdf

WWF Network. (2019). Extended Producer Responsibility (EPR) For Plastic Packaging.

WWF-Singapore. (2020). Plastic ACTion (PACT). Retrieved from https://plasticaction.asia/?utm_source=corewebsite\&utm_medium=homepage_dropdown_menu

Xanthos, D., \& Walker, T. (2017). International policies to reduce plastic marine pollution from single-use plastics (plastic bags and microbeads): A review. Marine Pollution Bulletin. doi:10.1016/j.marpolbul.2017.02.048

Yano, J., Hirai, Y., \& Sakai, S. (2014). Greenhouse gas emissions from the treatment of household plastic containers and packaging: replacement with biomass-based materials. Waste Management \& Research, 32(4), 304-316. doi:10.1177/0734242X14525820 
Marine Debris Mitigation - Plastic Neutrality through a Credit System in Southeast Asia [Author] 